\title{
Evidence for adverse reproductive outcomes among women microelectronic assembly workers
}

\author{
G Huel, D Mergler, R Bowler
}

\begin{abstract}
Microelectronics assembly entails complex processes where several potentially fetotoxic chemical compounds are used extensively. This study was undertaken to assess the potential adverse reproductive outcomes among former women workers in a microelectronics assembly plant in New Mexico with respect to a comparable population from the same geographical region and to examine the relation between these outcomes and employment history in this plant. After matching a pool of 143 former microelectronic female workers and 105 referents, 90 former microelectronic female worker-referent pairs were constituted (representing 302 and 324 pregnancies in former workers and referents respectively). The odds ratio (for pair matching design) of spontaneous abortion among women workers, before beginning to assemble microelectronic components, was $0.9\left(\chi^{2}=0.04 ; \mathrm{NS}\right)$. After the beginning of employment this odds ratio became $5.6\left(\chi^{2}=9.8 ; p<1 \%\right)$. This estimated odds ratio decreased to $4 \cdot 0$, taking into account the increased risk for spontaneous abortion in previous pregnancies before employment $\left(\chi^{2}=\right.$ $5 \cdot 4 ; p<5 \%)$. It was not possible to determine if this effect was reversible owing to the small number of pairs available after employment. The findings of this study corroborate the results of former studies that suggest a potential association between electronic manufacturing activity and risk of spontaneous abortion. Although the organic solvents were suspected of being the potential risk factor, this study was inconclusive from this point of view. Nevertheless, these investigations may provide
\end{abstract}

Groupe de recherche-action en biologie du travail, Quebec Institute for Research in Occupational Health and Safety, Université du Québec à Montréal, Montreal, Quebec, Canada H3C 3 P8

G Huel, D Mergler

Occupational Medicine Clinic, San Francisco General Hospital, University of California, San Francisco, California, USA

R Bowler some insight into reproductive outcomes among female workers exposed to solvents.

The microelectronics industry, which employs large numbers of women, purports to be a "clean" industry. Paradoxically, many potential genotoxic and응 fetotoxic chemicals are used both in manufacturing 은 and assembling semiconductor electronic com- ponents and printed circuit boards. Analysis of reproductive outcomes among Finnish women work- $\vec{\Phi}$ ing in the main sectors of the metal industry showed $\overrightarrow{0}$ that the frequency of spontaneous abortions was $\Theta$ increased in electronics plants. ${ }^{1}$ The particular group at risk appeared to be solderers exposed to the vapours of solder resin; however, the specific risk factors could not be identified. A major source of occupational exposure to solvents for women is in the $\frac{O}{0}$ electronics industries, where these substances are $\stackrel{\mathbb{D}}{2}$ extensively used as cleaning agents. A Finnish case- $\overrightarrow{\vec{O}}$ control study showed a significant increase in the rate 3 of spontaneous abortion among women with exposure to occupational organic solvents. ${ }^{2}$ More? recently, adverse reproductive outcomes were 0 examined in a population of manufacturing workers $\stackrel{\mathbb{S}}{3}$ at a semiconductor plant in Massachusetts. ${ }^{3}$ The data reported indicate a positive association between employment in semiconductor manufacturing and risk for spontaneous abortion; however, it was inconclusive about specific activity and potential fetotoxico agents. Industrial hygiene data showed that glycol $\rightarrow$ ether exposure levels were below United States? industrial standards.

Chemical health hazards faced by workers in the N $^{\circ}$ electronics industry include solvents, ${ }^{4}$ gases, acids, $\mathbb{O}$ and metals. Industrial hygiene surveys have N documented exposures to chlorofluorocarbons, iso- 0 propanol, n-butylacetate, xylene, acetone, methanol, petroleum distillates, and trichloroethylene. ${ }^{5-8}$ Since $\frac{\mathrm{C}}{0}$ these chemicals are often used in mixtures and are $\stackrel{\oplus}{+}$ frequently changed, it seems difficult to identify the 0 specific potential fetotoxic factors. Nevertheless, $\overrightarrow{0}$

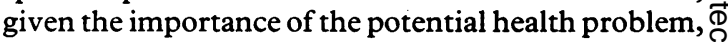
the association between microelectronics manufac- $\vec{\nabla}$ turing and risk of spontaneous abortion was considered to need confirmation.

The present study was undertaken to assess the 
potential adverse reproductive outcomes among former women workers in a microelectronics assembly plant with respect to a comparable population from the same geographical region, with no history of such an exposure, and to examine the relation between these outcomes and employment history in this plant.

\section{Material and methods}

STUDY DESIGN

Although it is possible to use multivariate statistical analysis, such as logistic regression, to take into account confounding variables, matched paired design at time of sampling also provides a way of considering a wide number of possible confounders which it would be impossible to take into account. The choice of one method over the other affects potential bias for risk evaluation as well as the precision of the risk estimation. ${ }^{9}$ Logistic regression which favours better precision to the detriment of bias is useful for detecting new risk factors. Since this was not the objective of the present study, it was more appropriate to minimise bias in the measure while sacrificing some precision in risk estimation.

The choice of a matching design may lead to efficient adjustment for potentially confounding effects of a wide range of social and economic factors that would be difficult, if not impossible, to measure and hence to control. Moreover, having the reproductive history before employment, the design was particularly well fitted to control the fullness of potential bias on the inference of the results, since the main characteristics of the two groups have to be similar before employment.

\section{POPULATION}

The workers in the present study had been employed in a microelectronics plant that had opened in 1971 and had employed 3371 workers (including office, technical, management, and production personnel) between 1971 and 1984. At the time of the study over 100 workers (male and female) had received compensation on the basis of multiple health problems. ${ }^{10}$ Reproductive history of these former workers who had been hired at different periods between 1971 and 1983 and a reference population, made up of friends and relatives of the former workers, was obtained through a self administered questionnaire, including sociodemographic data (age, sex, years of education, and ethnicity), previous and current work history, and information such as hobbies, current use and type of medication, drinking, and smoking habits. From the initial 144 former female workers and 133 female referents, who participated in the study, one exposed and 28 referents were excluded from the present analysis for past workplace chemical employment other than in this particular microelectronics plant. The final group comprised 143 former workers having at least one pregnancy (518 pregnancies) and 105 referents (368 pregnancies).

Dates of employment in this microelectronics plant were obtained from company records. Matched pairs were created before employment on the following basis: ethnicity, mother's age, and number of pregnancies; thus for each exposed mother a control was chosen according to the ethnic group (caucasian, hispanic, or other), the nearest age ( \pm 3 years under age $45, \pm 6$ years over), the number of pregnancies ( 0 to 5,6 and more were considered as 6 ) before the beginning of employment (figure). On the basis of this process, 53 exposed mothers could not be paired owing to matching constraints. The study was thus founded on 90 pairs. Four periods of employment were considered: (1) before working in the plant, and (2) since working in the plant: $(a)$ while employed in the plant, and $(b)$ after termination of employment.

\section{STATISTICAL ANALYSIS}

The statistical unit used in this study is the mother and not the pregnancy for the obvious reason of statistical independency: women who have had one spontaneous abortion are at increased risk of having another when compared with women who have not had a spontaneous abortion. ${ }^{11}{ }^{12}$ Mothers were classified as having had a spontaneous abortion when at least one pregnancy terminated in a spontaneous abortion during the considered period. Spontaneous abortion was defined as "diagnosed miscarriages"

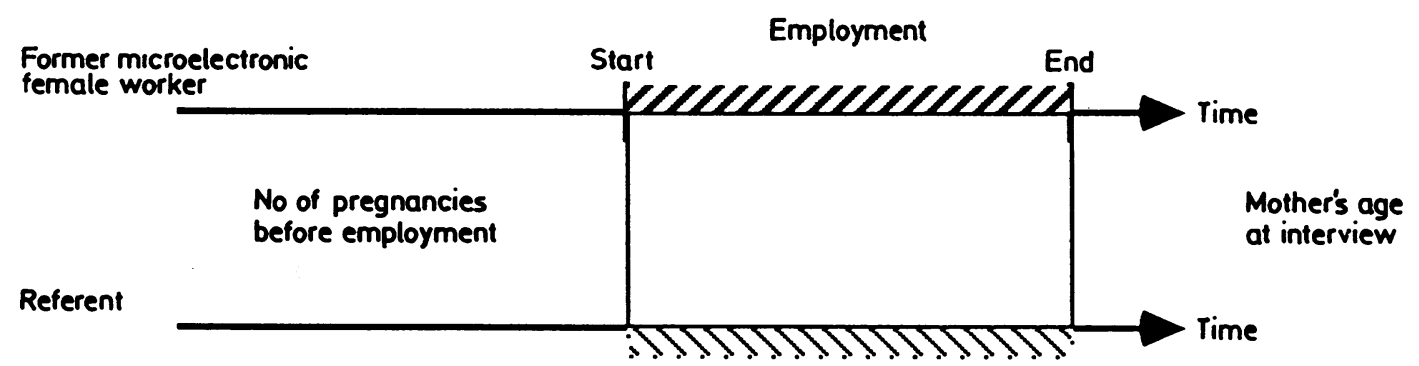


and the name of the consulting physician was indicated. For each period the population was constituted by pairs in which both mothers were pregnant during that period. Thus pairs in which one member became sterile were weeded out. The odds ratio for matched pairs was estimated as follows: suppose that $a_{10}$ is the number of exposed-unexposed pairs in which the exposed mother had had at least one spontaneous abortion during the considered period, and $\mathrm{a}_{01}$ such number in the reverse case. The maximum likelihood estimator of the population odds ratio is given as usual by

$$
a_{10} / a_{01}
$$

The McNemar test statistic was used to measure the significance level of the odds ratio.

\section{Results \\ DESCRIPTION OF REPRODUCTIVE OUTCOMES \\ Before matching}

Before matching and without considering period of employment, the initial population included 48 former microelectronic female workers out of $143(34 \%)$ with at least one spontaneous abortion at interview. The former microelectronic female workers population reported a total of 92 spontaneous abortions out of 518 pregnancies $(18 \%)$. Among the 105 referent mothers, $22(21 \%)$ had suffered at least one spontaneous abortion at interview. This referent population reported 30 spontaneous abortions out of 368 pregnancies $\left(8_{0}^{\circ}\right)$.

\section{After matching}

After matching, 90 former microelectronic female worker-referent pairs were constituted. Of these, there were 73 pairs where both mothers were pregnant at least once before employment (which represent 205 and 232 pregnancies in exposed and referents respectively); 17 pairs were composed of workers who were pregnant for the first time after employment. Fifty seven pairs out of 90 did not appear in the analysis "after employment" because only one of the former microelectronic female work- $-\stackrel{\Phi}{-}$ ers or referent members was pregnant after em- $\Rightarrow$ ployment. For 33 pairs both former microelectronic $\stackrel{\text { ? }}{+}$ female workers and referent members had had at least one pregnancy after starting employment. Of these 33, 25 occurred during the period of employment and eight afterwards.

Table 1 shows the descriptive characteristics of the pairs. Comparisons showed good homogeneity for $-\vec{\circ}$ the control parameters (maternal age at pregnancies: before employment and at interview, educational $\vec{\omega}$ level of mother, and number of pregnancies before employment). Stillbirths occurred in two exposedळ and one referent respectively; there was one abortion? in each group. Before employment, of the 73 pairs, no $A$ spontaneous abortions had occurred in 50 pairs, spontaneous abortions were reported for each member of two pairs, a discrepancy occurred in 21 pairs. The ethnic composition of the population was: $70^{-}$ pairs hispanic, 19 pairs white, and one pair of black $\vec{c}$ female workers.

Table 2 shows the frequencies of women reporting ${ }^{\Phi}$ spontaneous abortions with respect to the period of $\vec{e}$ employment. The level of disagreement is showno before employment. Twenty one of 73 pairs for which both members were pregnant are in dis- $\sum^{\circ}$ agreement. The associated odds ratio was estimated to 0.9 which was not significant.

After the start of employment 20 of 33 pairs are in disagreement $\left(60^{\circ}{ }_{0}\right)$. These 20 discordant pairs were composed of 17 spontaneous abortions among for-음 mer microelectronic female workers with no spon- $-\frac{3}{2}$ taneous abortions among referents. The odds ratio associated was $5.6\left(\chi^{2}=9.8 ; p<1 \%\right)$.

For the same analysis, but restricted to pregnancies occurring during employment (pregnancies after? the end of employment were excluded), an odds ratio 3 of 15 was estimated $\left(\chi^{2}=12 \cdot 2 ; \mathrm{p}<1 \%\right)$. Although highly significant the precision of this odds ratio is $\frac{}{3}$ weak. Unfortunately, we were not able to test the reversibility of the phenomenon because of the few윽 number of pairs of pregnancies after ending $\rightarrow$ employment.

Table 1 Main characteristics of the 90 exposed and paired referent groups

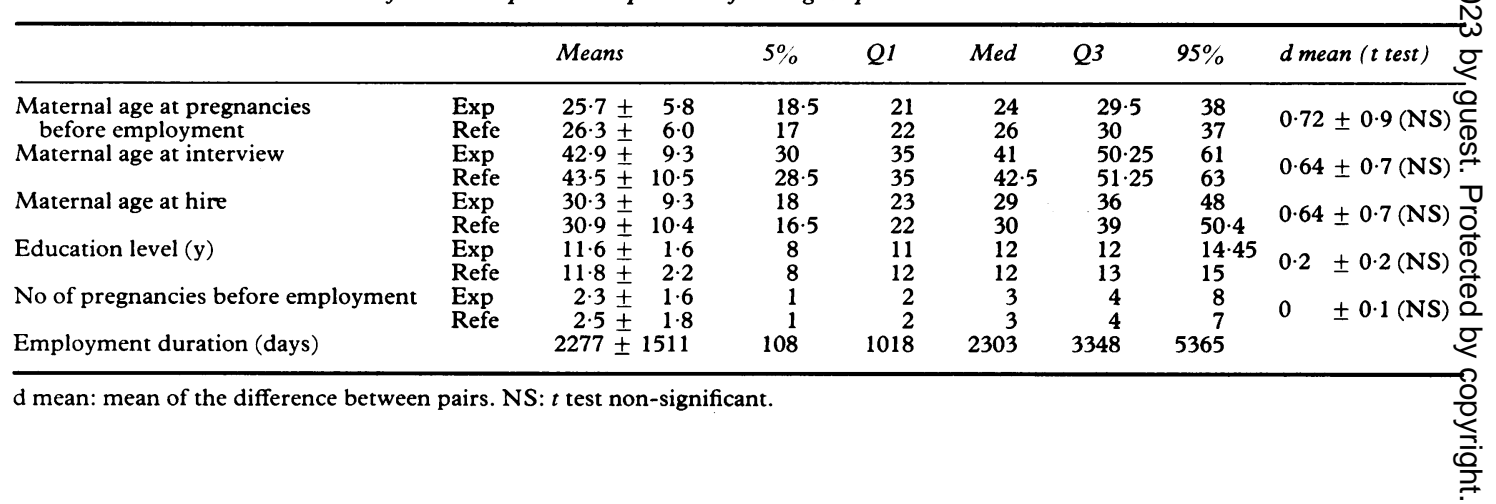


Table 2 Odds ratio using pair matching according to period of employment

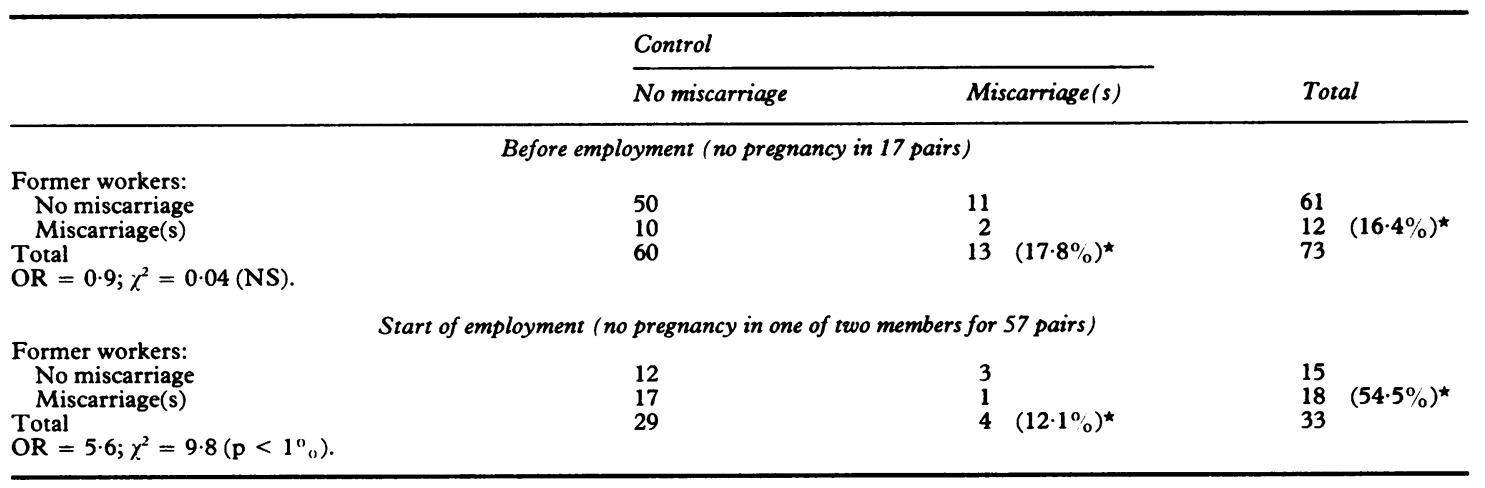

^ Per cent in row and column point to frequencies of spontaneous abortions in referent and former workers respectively.

To eliminate the potential effect of overestimation of workers who are at increased risk of having spontaneous abortion in one of the two groups, we excluded pairs for which one member suffered at least one spontaneous abortion before employment (table 3). The odds ratio decreased somewhat (OR = 4) but remained significant $\left(\chi^{2}=5 \cdot 4 ; p<5 \%\right)$.

\section{Discussion}

The results of this study indicate that the frequency of spontaneous abortions occurring while working in this microelectronics plant was significantly higher than frequency of spontaneous abortion in the absence of this employment. This increased frequency of miscarriages seems to be associated with employment in this microelectronics assembly plant. This result is similar to those reported in previous studies $^{13}$ and suggests that risk factor(s) associated with the electronic assembly process interfere with human fetal development.

The reported risks in the present study appeared higher than those reported by Pastides ${ }^{3}$ in a similar occupational activity. Nevertheless, it seems that the level of hygiene of the concerned plant was particularly harmful as related in previous reports. ${ }^{10}$

It would be interesting to compare individual departments. Most workers, however, were engaged in all aspects of the operation and rotated in accord- ance with production needs and their residual capabilities. ${ }^{10}$ Moreover, the operation was housed in a huge open area where all the manufacturing operations with the exception of crystal filters, thick fibres, and printed circuit laboratory were performed in the "open plant." Although no industrial hygiene samples were available, the list of chemicals used in the departments includes chorofluorocarbons (trichlorotrifluoroethane, dichlorodifluoromethane ...), chlorinated hydrocarbons (trichloroethylene, methyl chloride, and 1-1-1 trichloroethane), glycol ethers, isopropanol, acetone, toluene, xylene, and alcohol. These solvents were used in most work processes for cleaning, degreasing, and modifying epoxies and resins, as fluxing agents for soldering, for rinsing in etching and plating, and as thinners and dilutants. Transformers and other electronics components were dipped with bare hands into open degreasing containers. According to Fox, this work was associated with daily symptoms of intoxication, including headaches, lightheadedness, confusion, and fatigue, ${ }^{10}$ as well as irritant dermatitis of the hands which are well known symptoms of solvent intoxication. ${ }^{13}$

This investigation was subject to several limitations that should be further considered: (1) The referent population was not randomly selected but had been chosen by the microelectronic female workers. That could be a source of bias, for instance,

Table 3 Odds ratio using pair matching after the beginning of exposure

\begin{tabular}{|c|c|c|c|}
\hline & \multicolumn{2}{|l|}{ Control } & \multirow[b]{2}{*}{ Total } \\
\hline & No miscarriage & Miscarriage(s) & \\
\hline $\begin{array}{l}\text { Former workers: } \\
\text { No miscarriage } \\
\text { Miscarriage(s) } \\
\text { Total } \\
\text { OR }=4 ; \%^{2}=5.4\left(\mathrm{p}<5^{\circ}{ }_{0}\right)\end{array}$ & $\begin{array}{l}10 \\
12 \\
22\end{array}$ & $\begin{array}{ll}3 & \\
1 & \\
4 & (15 \cdot 3 \%)^{\star}\end{array}$ & $\begin{array}{l}13 \\
13(50 \%)^{\star} \\
26\end{array}$ \\
\hline
\end{tabular}

*Per cent in row and column point to frequencies of spontaneous abortions in referent and former workers respectively. 
a referent could be chosen because of her particular good health status. Nevertheless, a previous analysis of the medical history of the referents showed a prevalence of illness that seemed no less than expected. (R Bowler et al, unpublished data). Furthermore, the frequency of spontaneous abortion in the referent population $\left(8^{\circ}{ }_{0}\right)$ is slightly lower than usually met with in retrospective studies, often estimated to be $10-15^{\circ}{ }_{0} \cdot{ }^{14}$ Nevertheless, this point could be explained by the fact that our data were censored insofar as the reproductive life of the women stopped at interview. The increased risk of spontaneous abortions with maternal age is well known. ${ }^{15}$ The specific problems involved in reproductive occupational epidemiology has been considered and discussed extensively elsewhere. ${ }^{16}$ Recall bias should also be considered. From this point of view spontaneous abortions in former microelectronic female workers were clinically recognised when they occurred after employment. Before employment, if this bias existed it would be identical in former microelectronic female workers and referent groups. Therefore, comparison of spontaneous abortions in the two groups showed a similar frequency (13/73 $v 12 / 73$ respectively).

The choice of a matching design may lead to efficient adjustment for potentially confounding effects of a wide range of social and economic factors that would be difficult, if not impossible, to measure and hence to control, and this study design was particularly well fitted to minimise the implications of such bias on the inference of the result and assessing the fullness of the residual effect of the bias, if any. Thus, before employment, discrepancies between former microelectronic female workers and referents for each control parameter have to be minimised, as also the frequencies of spontaneous abortion. From this point of view, the characteristics of the two groups before the start of employment agreed with these considerations.

The findings of this study corroborate the results of previous studies ${ }^{13}$ which suggest a potential association between electronic manufacturing and the risk of spontaneous abortion. Unfortunately, although organic solvents were suspected of being the potential risk factor, these studies were incon $-\stackrel{\mathbb{D}}{\circ}$ clusive from this point of view; nevertheless, our investigations may provide some insight into the reproductive problem in female workers exposed to these materials.

1 Hemminki K, Franssila E, Vainio H. Spontaneous abortions among female chemical workers in Finland. Int Arch Occup Environ Health 1980;45:123-6.

2 Hemminki K, Niemi M-L, Koskinen K, Vainio H. Spontaneous $\overrightarrow{3}$ abortions among women employed in the metal industry irw Finland. Int Arch Occup Environ Health 1980;47:53-60.

3 Pastides H, Calabrese EJ, Hosmer DW Jr, Harris DR Jr: Spontaneous abortion and general illness symptoms among semiconductor manufacturers. J Occup Med 1988;30:543-51?

4 Cone JE. Health hazards of solvents. State of the art reviews Occup Med 1986;1:69-87.

5 National Institute for Occupational Health and Safety. Hazard evaluation and technical assistance report No 77-3-420. Kittan ing, Penn: Essex International, 1977.

6 National Institute for Occupational Health and Safety. Hazard evaluation and technical assistance report No TA 76-102? Grovelity Ohio: Robertshaw Controls, 1977.

7 Pasquini D, Laird L. Hazards assessment of the electroniccomponent manufacturing industry. Cincinnati: Nationaf Institute for Occupational Health and Safety, 1982. (ContractD No 210-80-0058.)

8 Wade R, Williams RM. Semiconductor industry study. Californiś Department of Industrial Relations, DLSH, Task Force on the Electronics Industry, 1981.

9 Kleinbaum DG, Kupper LL, Morgenstern H. Epidemiologid research: principles and quantitative methods. Belmonts California: Lifetime Learning Publications, 1982:446-56.

10 Fox S. Toxic chemicals and stress: anatomy of an out-of-cour settlement for women workers at GTE Lenkurt Electronics Planto Albuquerque: University of New Mexico, 1988. ( $\mathrm{PhD}$ thesis.

11 Warburton D, Fraser FC. Spontaneous abortion risks in manD data from reproductive histories collected in a medical gene $\rightarrow$ tics units. Am J Hum Genet 1964;16:1-24.

12 Leridon $\mathrm{H}$. Facts and artifacts in the study of intra-uterine mortality: a reconsideration from pregnancy histories. Popu lation Studies 1976;30:319-36.

13 Axelson $\mathrm{O}$, Hogstedt C. On the health effects of solvents. In Zenz C, ed. Occupational medicine: principles and practicaf applications. 2nd ed. Chicago: Year Book Medical Publishers 1988:775-84.

14 Carr DH. Detection and evaluation of pregnancy wastage. In: Wilson JP, Fraser FC, eds. Handbook of teratology. Vol 3. New York: Plenum Press, 1977:189-213.

15 Kline JK. Maternal occupation: effects on spontaneous abor? tions and malformations. In: Stein $\mathrm{ZA}$, Hatch MC, eds Reproductive problems in the workplace. Philadelphia: Hanles and Belfus, 1986:381-403.

16 Hemminki K, Axelson O, Niemi M-L, Ahlborg G. Assessmen? of methods and results of reproductive occupational epi demiology: spontaneous abortions and malformations in the offspring of working women. Am J Ind Med 1983;4:293-307

Accepted 6 November 1989 